\title{
Hans Kelsen
}

\section{Reine Rechtslehre}

Einleitung in die rechtswissenschaftliche Problematik (Studienausgabe der 1. Auflage 1934)

hrsg. u. eingel. v. Matthias Jestaedt

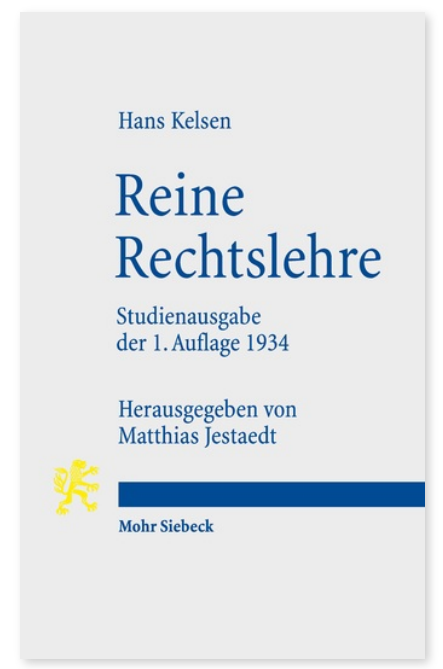

2008. LXVI, 181 Seiten.

ISBN 978-3-16-156465-9

DOI 10.1628/978-3-16-156465-9

eBook PDF

ISBN 978-3-16-149703-2

fadengeheftete Broschur 19,00€
Bei dem vorliegenden Band handelt es sich um eine Studienausgabe der von Hans Kelsen im Jahre 1934 vorgelegten »Reine[n] Rechtslehre«. Dieses Werk gehört zweifelsohne zu den rechtstheoretischen Schlüsselschriften des 20. Jahrhunderts. In ihm entwickelt Kelsen erstmals im systematischen Zusammenhang seine einerseits das Recht von der Moral, andererseits die Norm vom Faktum konsequent scheidende Rechtstheorie. Wer auf der Höhe der Zeit über Struktur und Geltung von Recht und die Eigenart von Rechtswissenschaft, kurz: wer über das Rechtliche am Recht nachdenken will, kommt an der »Reine[n] Rechtslehre« nicht vorbei. Gleichviel, ob und inwieweit man dem ideologiekritischen Positivismus der »Wiener Schule der Rechtstheorie« zuzustimmen geneigt ist oder nicht, gibt diese erste Gesamtdarstellung von Kelsens Rechtslehre ein Reflexionsniveau vor, hinter welches der rechtstheoretische Diskurs nicht zurückfallen sollte.

Die Erstauflage der »Reine[n] Rechtslehre«, die weltweit in rund ein Dutzend Sprachen übersetzt worden ist, wurde in deutscher Sprache mehrfach nachgedruckt, ist indes derzeit vergriffen. Sie wird hier in Gestalt einer mit einer ausführlichen Einleitung versehenen Studienausgabe vorgelegt, die am Studium des Rechts Interessierte zum Hineinlesen ermutigen und zum kritischen Nach- und Weiterdenken einladen möchte.

Hans Kelsen (1881-1973) 1919-30 Universitätsprofessor in Wien; 1919-1930 Verfassungsrichter; 1930-33 Professor in Köln; 1933-40 Professor in Genf; 1936-38 Professor in Prag; 1945-52 Professor in Berkeley.

Matthias Jestaedt ist Professor für Öffentliches Recht und Rechtstheorie an der Albert-Ludwigs-Universität Freiburg.

Jetzt bestellen:

https://mohrsiebeck.com/buch/reine-rechtslehre-9783161564659?no_cache=1

order@mohrsiebeck.com

Telefon: +49 (0)7071-923-17

Telefax: +49 (0)7071-51104 